\title{
PREVALÊNCIA DOS PRINCIPAIS SINAIS CLÍNICOS EM CÃES SUSPEITOS DE CINOMOSE ATENDIDOS NA CLÍNICA MÉDICA VETERINÁRIA DO UNIFOR EM FORMIGA-MG
}

\author{
Marilene de F. Borges Santos \\ Discente do curso de Medicina Veterinária do UNIFOR \\ Raquel Ribeiro Dias Santos \\ Professora do UNIFOR \\ José Antônio Viana \\ Professor do UNIFOR
}

Recebido em: 28/02/2012

Aprovado em: 25/04/12

\begin{abstract}
RESUMO
A cinomose canina é uma doença infecto-contagiosa que acomete cães e outros canídeos. As fichas clínicas de 582 cães que foram atendidos na clínica médica veterinária do UNIFOR-MG, durante o período de março de 2010 a julho de 2011, foram revisadas à procura de casos suspeitos de cinomose. Vinte e duas $(3,78 \%)$ fichas foram selecionadas, tendo como base o diagnóstico do médico veterinário responsável. Dos 22 casos, foram anotadas informações referentes à idade, sexo, histórico de vacinação e sinais clínicos. Os sinais clínicos foram correlacionados como sistêmicos e neurológicos, em que a oftalmorreia e a mioclonia, respectivamente, foram as alterações de maior prevalência. Do total de casos suspeitos, 86,4\% dos cães não apresentavam histórico de vacinação e 54,5\% eram cães machos. Os resultados mostraram que cães não vacinados apresentaram maior susceptibilidade à infecção pelo vírus da cinomose canina (VCC), porém, não variando a gravidade da doença entre os cães envolvidos. Os sinais clínicos mostraram-se inespecíficos devido à sua semelhança com outras enfermidades, podendo considerar que sinais sistêmicos, quando apresentados isoladamente, não contribuem para um diagnóstico conclusivo de cinomose canina.
\end{abstract}

Palavras-chave: Cinomose. Sinais clínicos. Prevalência.

\section{PREVALENCE OF MAJOR CLINICAL SIGNS OF DISTEMPER IN SUPECTS DOGS SERVED IN VETERINARY MEDICAL CLINIC (CLIMVET) OF UNIFOR IN FORMIGA/MG}

\begin{abstract}
Canine Distemper is an infectious disease that affects dogs and other canids. The medical records of 582 dogs that were treated at the veterinary clinic of UNIFOR-MG, during the period March 2010 to July 2011, were reviewed in search of suspected distemper. Twenty-two records (3.78\%) were selected,
\end{abstract}


based on the diagnosis of the attending veterinarian. Of the 22 cases were recorded information about age, sex, vaccination history and clinical signs. Clinical signs were correlated as systemic and neurological disorders, and myoclonus and oftalmorreia, respectively, were the changes of most prevalent. Of the total suspected cases, $86.4 \%$ of dogs had no history of vaccination and $54.5 \%$ were male dogs. The results showed that unvaccinated dogs showed increased susceptibility to infection with canine distemper virus (VCC), however, varying disease severity among the dogs involved. Clinical signs proved to be nonspecific due to its similarity to other diseases, and it can be considered that systemic signs, when presented alone, do not contribute to a conclusive diagnosis of canine distemper.

Keywords: Distemper. Clinical signs. Prevalence.

\section{INTRODUÇÃO}

A cinomose canina é uma doença viral severa e altamente contagiosa que acomete cães e outros carnívoros de forma multissistêmica (ETTINGER; FELDMAN, 2004). O vírus pertence à família Paramyxoviridae gênero morbilivírus, caracterizado como vírus pantrópico, estreitamente relacionado ao vírus da peste bovina e do sarampo humano (QUINN et al, 2005).

A cinomose apresenta distribuição mundial e pode acometer cães de todas as idades, raça e sexo. No entanto, sua incidência é mais elevada em animais até 06 meses de idade e não vacinados (SHERDING; BIRCHARD, 2008).

Os cães acometidos podem manifestar sinais clínicos multissistêmicos variáveis, estando estes sinais relacionados à virulência da cepa infectante e à resposta imunológica do hospedeiro (SHERDING; BIRCHARD, 2008).

A cinomose acomete primariamente o sistema respiratório, trato intestinal e o sistema nervoso dos cães. O comprometimento desses tecidos predispõe as infecções secundárias, além de prejudicar a atividade imunológica do organismo, interferindo na sua capacidade em debelar a infecção. (LEGENDRE, 2004).

O grau de comprometimento do sistema nervoso central depende da cepa viral, da idade e da imunocompetência do cão, em que o animal pode apresentar sinais clínicos variáveis, relacionados à região do SNC afetada. Muitas vezes, os sinais clínicos apresentam-se de forma grave, incompatíveis com a vida do animal. Desta forma, a cinomose é considerada uma das principais doenças causadoras de mortes e razão para indicação de eutanásias. (FIGHERA et al, 2008).

O diagnóstico da cinomose canina é presumível, devido à ausência de sinais clínicos específicos, necessitando de exames laboratoriais como métodos auxiliares para um diagnóstico conclusivo desta enfermidade (SHERDING; BIRCHARD, 2008). 
O objetivo deste trabalho é descrever os principais sinais clínicos de cães suspeitos de cinomose, atendidos na Clínica Veterinária (CLIMVET) do Centro Universitário de Formiga (UNIFOR/MG).

\section{MATERIAIS E MÉTODOS}

As fichas dos atendimentos clínicos ocorridos na CLIMVET do UNIFOR refere-se o período de março de 2010 a julho de 2011, onde foram analisadas casos suspeitos de cinomose, conforme permitido pela coordenação geral de laboratórios.

Durante este período, ocorreram 582 atendimentos clínicos. 22 destes obtiveram, do médico veterinário responsável, diagnóstico clínico sugestivo de cinomose. Estes casos foram selecionados e anotados em fichas, buscando informações referentes à idade, sinais clínicos, sexo e vacinação.

Os sinais clínicos foram anotados conforme ocorrência nas fichas clínicas pelo médico veterinário responsável.

Quanto à idade, os cães foram divididos em três categorias de acordo com a literatura internacional (GOLDSTON; HOSKINS, 1999) em filhotes (até 01 ano de idade), adultos (de 1 a 9 anos de idade) e idosos (a partir de 10 anos de idade).

Os dados obtidos (idade, vacinação, sinais clínicos e sexo) foram tabulados no programa Excel, em que os sinais clínicos foram correlacionados em sistêmicos e neurológicos e, após, subdivididos conforme a prevalência dos sistemas acometidos (respiratório, gastrointestinal, oftálmico e dermatológico).

\section{RESULTADOS E DISCUSSÕES}

Dos 582 atendimentos clínicos realizados na clínica médica veterinária (CLIMVET) do UNIFOR/MG, 22 (3,78\%) foram relacionados como cães suspeitos de cinomose.

Do total de casos suspeitos, 10/22 (45,5\%) eram filhotes e 12/22 (54,5\%) eram adultos, segundo a classificação proposta por Goldston e Hoskins (1999). O resultado deste estudo indica que dentre o total de casos suspeitos de cinomose, os adultos (12/22) foram a faixa etária mais acometida, sendo o mesmo observado por Vicente, Abreu e Passos (2010), em estudo realizado em 30 cães naturalmente infectados pelo VCC, em que os cães adultos foram mais acometidos em relação aos filhotes, sendo $50 \%$ e 36,6\%, respectivamente. Ao contrário de Sonne et al (2009), que observaram em seu estudo 
utilizando 54 cães, que a maior incidência ocorreu em filhotes, representando 90,3\% dos casos. A literatura (CATROXO, 2003; ETTINGER; FELDMAN, 2004; SHERDING; NELSON; COUTO, 2006; BIRCHARD, 2008; menciona os filhotes como a faixa etária mais acometida, devido ao maior grau de susceptibilidade.

Porém, os autores que correlacionam casos de cinomose por faixa etária (ETTINGER; FELDMAN, 2004; NELSON; COUTO, 2006; SHERDING; BIRCHARD, 2008) não especificaram os limites utilizados para classificar cada uma delas. Os cães idosos, ou seja, acima de 10 anos não foram relacionados neste trabalho, devido a nenhum cão com esta faixa etária ter apresentado quadro clínico sugestivo de cinomose nos atendimentos clínicos na CLIMVET.

Dos 22 casos clínicos, 18 (81,2\%) apresentaram distúrbios neurológicos, sendo que dentre eles, $9(50 \%)$ eram filhotes e $9(50 \%)$ eram adultos.

A faixa etária neste estudo não apresentou diferenças quanto ao grau de susceptibilidade. Diferente do que foi apresentado por Silva et al (2007), que correlacionaram os filhotes como a faixa etária que mais desenvolveu distúrbios neurológicos, sendo que dentre 608 cães avaliados, com idade esclarecida, estes representaram $49,5 \%$ dos casos.

Dos 18 cães que apresentaram distúrbios neurológicos, a mioclonia foi a de maior prevalência, representando 59,0\% dos casos, sendo o mesmo observado por Silva et al (2007); Tudury et al (1997); Negrão et al (2007); Gebara et al (2004a e 2004b); além de Sherding e Birchard (2008); Ettinger e Feldman (2004); Nelson e Couto (2006); Jones et al (2000); Lorenz e Kornegay (2006) que mencionaram a cinomose canina como a causa mais comum da mioclonia. Este transtorno neurológico é considerado para alguns autores como patognomônico da cinomose canina, porém segundo Monteiro et al. (2010), ela também pode ser observada em outros distúrbios do SNC. No entanto, são patologias raras e algumas restritas a determinadas raças (LORENZ; KORNEGAY, 2006).

A mioclonia por cinomose foi identificada e descrita em 1862, sendo denominada coréia e síndrome do espasmo flexor. O quadro é caracterizado por contrações repetitivas e rítmicas de um grupo de músculos, sendo mais frequente aos músculos faciais ou músculos da mastigação (LORENZ; KORNEGAY, 2006).

Outros sinais neurológicos observados foram apresentados em menor frequência em relação à mioclonia, como, distúrbios cerebrais, motores e posturais, vestibulares e cerebelares e alterações comportamentais (TAB. 1.), conforme sinais também observados por Silva et al (2007) e Tudury et al (2007).

Os cães com deficiência de anticorpos geralmente apresentam transtornos nervosos mais graves e progressivos, tornando incompatíveis com a vida (NELSON; COUTO, 2006). Quase sempre nas 
infecções pelo VCC, o vírus atinge o encéfalo, mesmo que o animal não apresente manifestações de disfunções neurológicas, indicando que a progressão da fase sistêmica para a nervosa decorre de falhas do organismo em eliminar o vírus do SNC (MORO et al, 2004). Porém em alguns casos, o envolvimento neurológico pode ser a única manifestação clínica aparente da infecção (SHERDING; BIRCHARD, 2008), indicando que o quadro neuropatológico é dependente da vulnerabilidade do animal (MORO et al, 2004).

Tabela 1 - Frequência dos sinais neurológicos dos cães suspeitos de cinomose atendidos na CLIMVET durante o período de março/2010 a julho/2011.

\begin{tabular}{lccccc}
\hline \multicolumn{1}{c}{ Achados } & $\begin{array}{c}\text { Filhotes } \\
\text { não } \\
\text { vacinados } \\
\mathbf{\%}(\mathbf{n = 9})\end{array}$ & $\begin{array}{c}\text { Filhotes } \\
\mathbf{v a c i n a d o s} \\
\mathbf{\%}(\mathbf{n = 1})\end{array}$ & $\begin{array}{c}\text { Adultos } \\
\text { não } \\
\text { vacinados } \\
\mathbf{\%}(\mathbf{n = 1 0})\end{array}$ & $\begin{array}{c}\text { Adultos } \\
\text { vacinados } \\
\mathbf{\%}(\mathbf{n = 2})\end{array}$ & $\begin{array}{c}\text { Total } \\
\mathbf{\%} \\
(\mathbf{n = 2 2})\end{array}$ \\
\hline Depressão & $33,3(3)$ & - & $30,0(3)$ & - & $\begin{array}{c}27,3 \\
(6)\end{array}$ \\
Incoordenação motora & - & - & $20,0(2)$ & $50,0(1)$ & $\begin{array}{c}13,6 \\
(3)\end{array}$ \\
Ataxia & $22,2(2)$ & - & $30,0(3)$ & $50,0(1)$ & $\begin{array}{c}27,3 \\
(6)\end{array}$ \\
Mioclonia & $88,9(8)$ & - & $50,0(5)$ & - & $\begin{array}{c}59,0 \\
(13)\end{array}$ \\
Paralisia & - & - & $20,0(2)$ & - & $9,1(2)$ \\
Midríase & - & - & $10,0(1)$ & - & $4,5(1)$ \\
Convulsão & - & - & - & $50,0(1)$ & $4,5(1)$ \\
Desorientação & - & - & $10,0(1)$ & - & $4,5(1)$ \\
Vocalização & - & - & $10,0(1)$ & - & $4,5(1)$ \\
Sialorréia & - & - & $10,0(1)$ & - & $4,5(1)$ \\
\hline
\end{tabular}

Os sinais clínicos sistêmicos podem ser acompanhados na TAB. 2 onde a maior ocorrência observada foi secreção ocular (oftalmorreia), atingindo 9/22 (40,9\%) dos animais suspeitos. Semelhante aos resultados apresentados por Tudury et al (1997) e Sonne et al (2009), em que as alterações oftálmicas apresentaram-se também com maior frequência, seguidas por alterações gastrointestinais, respiratórias e dermatológicas. Os mesmos sintomas foram observados por Negrão et al (2007), Gebara et al (2004a e 2004b), porém em seus estudos, estes não foram correlacionadas por ordem de prevalência.

De acordo com Gebara et al (2004b), em situações em que os sinais sistêmicos são concomitantes aos neurológicos, como a mioclonia, o diagnóstico conclusivo pode ser dado com maior 
certeza. Porém, segundo Nelson e Couto (2006), os sinais sistêmicos da doença não são reconhecidos em aproximadamente $30 \%$ dos cães, devido às semelhanças com outras enfermidades.

Tabela 2. Frequência dos sinais sistêmicos dos cães suspeitos de cinomose atendidos na CLIMVET durante o período de março/2010 a julho /2011.

\begin{tabular}{|c|c|c|c|c|c|}
\hline Achados & $\begin{array}{c}\text { Filhotes } \\
\text { não } \\
\text { vacinados } \\
\%(\mathbf{n}=9) \\
\end{array}$ & $\begin{array}{c}\text { Filhotes } \\
\text { vacinados } \\
\%(\mathbf{n}=\mathbf{1}) \\
\end{array}$ & $\begin{array}{c}\text { Adultos } \\
\text { não } \\
\text { vacinados } \\
\%(\mathbf{n}=10)\end{array}$ & $\begin{array}{c}\text { Adultos } \\
\text { vacinados } \\
\%(\mathbf{n}=\mathbf{2}) \\
\end{array}$ & $\begin{array}{c}\text { Total } \\
\% \\
(n=22)\end{array}$ \\
\hline Inapetência & - & - & $10,0(1)$ & - & $4,5(1)$ \\
\hline Anorexia & $22,2(2)$ & $100,0(1)$ & $10,0(1)$ & $50,0(1)$ & $\begin{array}{c}22,7 \\
(5)\end{array}$ \\
\hline Diarréia & - & - & $10,0(1)$ & $50,0(1)$ & $9,1(2)$ \\
\hline Vômito & $11,1(1)$ & $100,0(1)$ & - & $50,0(1)$ & $\begin{array}{c}13,6 \\
(3)\end{array}$ \\
\hline Dispnéia & - & - & $10,0(1)$ & - & $4,5(1)$ \\
\hline Pneumonia & - & - & $10,0(1)$ & - & $4,5(1)$ \\
\hline Espirros & $11,1(1)$ & - & - & - & $4,5(1)$ \\
\hline $\begin{array}{l}\text { Secreção nasal } \\
\text { Pústulas }\end{array}$ & - & - & $10,0(1)$ & - & $4,5(1)$ \\
\hline abdominais & $11,1(1)$ & & - & - & $4,5(1)$ \\
\hline $\begin{array}{l}\text { Hiperceratose } \\
\text { Secreção }\end{array}$ & - & - & $10,0(1)$ & - & $4,5(1)$ \\
\hline $\begin{array}{l}\text { ocular } \\
\text { Úlcera de }\end{array}$ & $44,4(4)$ & $100,0(1)$ & $30,0(3)$ & $50,0(1)$ & $\begin{array}{c}40,9 \\
(9)\end{array}$ \\
\hline córnea & $11,1(1)$ & - & - & $50,0(1)$ & $9,1(2)$ \\
\hline Conjuntivite & $11,1(1)$ & $100,0(1)$ & $20,0(2)$ & - & $\begin{array}{c}18,2 \\
(4)\end{array}$ \\
\hline
\end{tabular}

Em relação ao histórico vacinal, o percentual de 19/22 (86,4\%) cães não vacinados e 3/22 $(13,6 \%)$ vacinados apresentados neste trabalho, concordam com Legendre (2004), Sherding e Birchard (2008), Jones et al (2000) que mencionam os animais não vacinados como aqueles mais susceptíveis à infecção. Dezengrini, Weiblen e Flores (2007) comprovaram, em estudo para avaliar a soroprevalência de várias infecções virais, que grande parte da população canina de Santa Maria/RS, sem histórico de vacinação, apresentou-se soronegativa ao VCC, portanto, considerados animais susceptíveis a contraírem esta enfermidade.

A vacinação é uma medida imunoprofilática contra o VCC, porém, de acordo com Hass et al. (2008), se a vacinação for realizada em animais muito jovens, os anticorpos maternos podem interferir no desenvolvimento de uma imunidade ativa. Segundo Monteiro et al (2010), é necessária uma 
avaliação prévia dos animais antes da vacinação, em busca de fatores que possam influenciar na resposta pós-vacinal eficaz, como hipertermia, doenças imunomediadas, dentre outros.

Segundo Biazzono, Hagiwara e Corrêa (2001), o cão deve ser vacinado quando se torna soronegativo, ou seja, entre a sexta e oitava semana de vida, para assegurar uma elevada resposta sorológica pós-vacinal, como foi observado por eles em pesquisa com filhotes oriundos de cadelas adequadamente imunizadas, onde a síntese de anticorpos apresentou-se elevada logo após a primovacinação realizada durante este período.

Em relação ao sexo, neste estudo, os machos apresentaram pouco mais susceptíveis, representando 12/22 (54,5\%) dos casos. Enquanto que Sonne et al (2009) observaram, em estudo com 54 cães, maior prevalência em machos, que representaram 32/54 (59,26\%) dos casos, porém, não sendo discutido em seu trabalho a razão para esta ocorrência.

\section{CONCLUSÃO}

Com base nos dados obtidos neste trabalho, observou-se que cães não vacinados apresentaram maior susceptibilidade à infecção pelo VCC. A gravidade da doença apresentou-se igual, independente do sexo e faixa etária dos cães envolvidos, tendo a mioclonia como distúrbio neurológico de maior prevalência e a oftalmorreia o principal sinal sistêmico apresentado. Os sinais mostraram-se inespecíficos devido à sua semelhança com outras enfermidades, considerando que os sinais sistêmicos quando apresentados isoladamente não contribuem para um diagnóstico conclusivo de cinomose canina, sugerindo exames laboratoriais complementares para esta definição.

\section{REFERÊNCIAS}

BIAZZONO, L.; HAGIWARA M. K.; CORRÊA A. R. Avaliação da resposta imune humoral em cães jovens imunizados contra a cinomose com vacina de vírus atenuado. Brazilian journal of veterinary research and animal science, São Paulo, v. 38, n. 5, p. 245-250, 2001.

BIRCHARD, J. S.; SHERDING, G. R. Manual Saunders: clínica de pequenos animais. 3. ed. São Paulo: Roca, 2008.

CATROXO, M. H. B. Cinomose canina: divulgação técnica. Biológico, São Paulo, v. 65, n. 1/2, p. 1-2, jan./dez., 2003. 
DEZENGRINI, R.; WEIBLEN R.; FLORES E. F. Soroprevalência das infecções por parvovírus, adenovírus, coronavírus canino e pelo vírus da cinomose em cães de Santa Maria, Rio Grande do Sul, Brasil. Ciência Rural, Santa Maria, v. 37, n. 1, p. 183-189, jan./fev. 2007.

ETTINGER. J. S.; FELDMAN. C. E. Tratado de medicina interna veterinária: doenças do cão e do gato. 5. ed. Rio de Janeiro: Guanabara Koogan, 2004. v. 1.

FIGHERA, R. A. et al. Causas de morte e razões para eutanásia de cães da Mesorregião do Centro Ocidental Rio-Grandense. Pesquisa veterinária brasileira, Rio de Janeiro, v. 28, n. 4, p. 223-230, abr. 2008.

GEBARA, C. M. S. et al. Lesões histológicas no sistema nervoso central de cães com encefalite e diagnóstico molecular da infecção pelo vírus da cinomose canina. Arquivo brasileiro de medicina veterinária e zootecnia, Belo Horizonte, v. 56, p. 168-174, $2004 \mathrm{a}$.

GEBARA, C. M. S. et al. Detecção do gene da nucleoproteína do vírus da cinomose canina por RTPCR em urina de cães com sinais clínicos de cinomose. Londrina, Arquivo brasileiro de medicina veterinária e zootecnia, Belo Horizonte, v. 56, p. 480-487, 2004b.

GOLDSTON, R.T; HOSKINS, J. D. Geriatria e gerontologia em cães e gatos. São Paulo: Roca, 1999.

HARTMANN, T. L. S. et al. Anticorpos neutralizantes contra os virus da cinomose e da parainfluenza em cães de canis dos municípios de Novo Hamburgo e Porto Alegre, RS, Brasil. Ciência rural, Santa Maria, v. 37, n. 4, p. 1178-1181, jul./ago. 2007.

HASS, R. et al. Níveis de anticorpos contra o vírus da cinomose canina e o parvovírus canino em cães não vacinados e vacinados. Arquivo brasileiro de medicina veterinária e zootecnia, Belo Horizonte, v. 60, n. 1 , p. $270-274,2008$.

HEADLEY, S. A.; GRAÇA, D. L. Canine distemper: epidemiological findings of 250 cases. Brazilian journal of veterinary research and animal science, São Paulo, v. 37, n. 2, 2000.

HIRSH D. C.; ZEE, Y. C. Microbiologia veterinária. Rio de Janeiro: Guanabara Koogan, 2003.

JONES, T. C. et al. Patologia veterinária. 6. ed. Barueri: Manole, 2000.

LORENZ M. D.; KORNEGAY, J. N. Neurologia veterinária. 4. ed. Barueri: Manole, 2006.

MONTEIRO, M. V. B. et al. Cinomose canina nos animais domésticos e silvestres: revisão. Revista de ciências agrárias, Amazonas, v. 53, n. 2, p. 216-223, jul./dez. 2010.

MORO, L. et al. Apoptose na desmielinização da cinomose canina: revisão de literatura. Bioscience Journal, Uberlândia, v. 20, n. 2, p. 171-178, maio/ago. 2004. 
NEGRÃO, F. J. et al. Avaliação da urina e de leucócitos como amostras biológicas para a detecção ante mortem do vírus da cinomose canina por RT-PCR em cães naturalmente infectados. Londrina, Arquivo brasileiro de medicina veterinária e zootecnia, Belo Horizonte, v. 59, n. 1, p. 253-257, 2007.

NELSON, R. W.; COUTO, C. G. Medicina interna de pequenos animais. 3. ed. São Paulo: Elsevier, 2006.

NOLETO, P. G. et al. Corpúsculos de Lentz em um cão com 10 dias de idade. Bioscience Journal, Uberlândia, v. 27, n. 1, p. 112-115, jan./fev. 2011.

QUINN. P. J. et al. Microbiologia veterinária e doenças infecciosas. São Paulo: Artmed, 2005.

REZENDE, R. S. et al. Análise microscópica do miocárdio ventricular esquerdo em cães soropositivos para cinomose. Pesquisa veterinária brasileira, Rio de Janeiro, v. 29, n. 2, p. 117-119, fev. 2009.

SCHWEIGERT, A. et al. Freqüência de corpúsculos de inclusão de Lentz em células sangüíneas e oculares de cães suspeitos de cinomose atendidos no Hospital Veterinário da Faculdade Integrado de Campo Mourão-PR. Campo digital, Campo Mourão, v. 1, n. 2, p. 90-92, jan./out. 2008.

SILVA, I. N. G. et al. Perfil hematológico e avaliação eletroforética das proteínas séricas de cães com cinomose. Arquivo brasileiro de medicina veterinária e zootecnia, Belo Horizonte, v. 57, n. 1, p. 136-139, 2005.

SILVA, M. C. et al. Aspectos clinicopatológicos de 620 casos neurológicos de cinomose em cães. Pesquisa veterinária brasileira, Rio de Janeiro, v. 27, n. 5, p. 215-220, maio 2007.

SONNE, L. et al. Achados patológicos e imuno-histoquímicos em cães, infectados naturalmente pelo vírus da cinomose canina. Pesquisa veterinária brasileira, Rio de Janeiro, v. 29, n. 2, p. 143-149, fev. 2009.

TIZARD, I. R. Imunologia veterinária. 6. ed. São Paulo: Roca, 2002.

TUDURY, A. E. et al. Observações clínicas e laboratoriais em cães com cinomose nervosa. Ciência Rural, Santa Maria, v. 27, n. 2 p. 229-235, 1997.

VAZ ,V. A. (Coord.). Manual de normalização de trabalhos acadêmicos. 3. ed. Formiga: Centro Universitário de Formiga, 2010.

VICENTE, A. F. et al. Perfil hematológico em cães infectados naturalmente por cinomose com presença de Corpúsculos de Sinegaglia Lentz, em Vassouras - RJ. Revista de Saúde, Vassouras, v. 1, n. 1, p. 49-54, jan./mar. 2010. 